\title{
The evolving role of intraoperative balloon pulmonary valvuloplasty in valve-sparing repair of tetralogy of Fallot
}

\author{
Joshua D. Robinson, MD, ${ }^{\mathrm{a}, \mathrm{c}}$ Rahul H. Rathod, MD, ${ }^{\mathrm{a}, \mathrm{c}}$ David W. Brown, MD, ${ }^{\mathrm{a}, \mathrm{c}}$ Pedro J. Del Nido, MD, ${ }^{\mathrm{b}, \mathrm{d}}$ \\ James E. Lock, MD, ${ }^{\mathrm{a}, \mathrm{c}}$ Doff B. McElhinney, MD, ${ }^{\mathrm{a}, \mathrm{c}}$ Emile A. Bacha, MD, ${ }^{\mathrm{b}, \mathrm{d}}$ and Audrey C. Marshall, MD ${ }^{\mathrm{a}, \mathrm{c}}$
}

Objective: The late morbidity of pulmonary regurgitation has intensified the interest in valve-sparing repair of tetralogy of Fallot. This study reviewed a single institution's experience with valve-sparing repair and investigated the role of intraoperative balloon valvuloplasty.

Methods: A retrospective chart review identified 238 patients who underwent complete primary repair of tetralogy of Fallot at less than 180 days of age. Patients were divided into 4 groups on the basis of the type of right ventricular outflow tract repair: transannular patch $(\mathrm{n}=111)$, commissurotomy or standard rigid dilation $(n=71)$, intraoperative balloon pulmonary valvuloplasty $(n=32)$, or no valvar intervention $(n=24)$.

Results: Baseline demographic and anatomic factors differed among the 4 procedural groups with substantial overlap. Among 142 patients with pulmonary valve hypoplasia ( $z$ score, -2 to -4$), 37 \%$ had valve-sparing repair. These patients had significant annular growth over time: $z$ score increased 0.67 and 1.00 per year in the intraoperative balloon valvuloplasty $(P<.001)$ and traditional valve-sparing $(P<.001)$ groups, respectively. Rates of valve growth did not differ across groups, but $z$ scores were 0.58 lower for the balloon valvuloplasty group across all time points $(P=.001)$. Freedom from reintervention and surgery was shorter for the balloon valvuloplasty group than for the other groups $(P<.001)$.

Conclusions: Patients with tetralogy of Fallot and pulmonary valve hypoplasia who undergo valve-sparing repair with intraoperative balloon valvuloplasty have significant longitudinal annular growth, with normalization of annular size over time. Despite application in patients with more hypoplastic valves, balloon valvuloplasty resulted in similar valve growth and pulmonary regurgitation as traditional methods, but higher rates of reintervention. Although the precise role of this technique needs further refinement, it is likely to be most useful in patients with moderate pulmonary stenosis and moderate pulmonary valve dysplasia. (J Thorac Cardiovasc Surg 2011;142:1367-73)

Tetralogy of Fallot (TOF) may be repaired using a variety of techniques. In cases of significant pulmonary valve (PV) hypoplasia, current approaches to right ventricular outflow tract (RVOT) reconstruction include transannular patch (TAP), commissurotomy, passage of rigid dilators, valve augmentation, or reconstruction and sequential intraoperative balloon pulmonary valvuloplasty (IBPV). ${ }^{1-4}$ TAP repair, in which the annulus is disrupted and enlarged, effectively relieves obstruction but results in significant pulmonary regurgitation (PR). The morbidity of PR over time has led to greater interest in $\mathrm{PV}$-sparing repair strategies, ${ }^{5-7}$ but enthusiasm for preserving valve architecture is balanced with concern for potential residual or recurrent valvar obstruction.

\footnotetext{
From the Departments of Cardiology ${ }^{\mathrm{a}}$ and Cardiac Surgery, ${ }^{\mathrm{b}}$ Children's Hospital, Boston, Mass; and Departments of Pediatrics ${ }^{\mathrm{c}}$ and Surgery, ${ }^{\mathrm{d}}$ Harvard Medical School, Boston, Mass.

Supported in part by the Skeffington Family Fund

Disclosures: Authors have nothing to disclose with regard to commercial support.

Received for publication Nov 22, 2010; revisions received Feb 9, 2011; accepted for publication Feb 23, 2011; available ahead of print June 27, 2011

Address for reprints: Emile A. Bacha, MD, Morgan Stanley Children's Hospital of New York-Presbyterian, Columbia University Medical Center, 3959 Broadway, CHN-274, New York, NY 10032 (E-mail: eb2709@columbia.edu). $0022-5223 / \$ 36.00$

Copyright (C) 2011 by The American Association for Thoracic Surgery doi:10.1016/j.jtcvs.2011.02.047
}

At the Children's Hospital, we have pursued a valvesparing technique using sharp commissurotomy followed by IBPV to relieve valvar obstruction in selected patients during the past 4 years. ${ }^{3}$ This strategy is based on several theoretic advantages and experience with transcatheter pulmonary valvuloplasty in animals and humans. A balloon can be introduced across the stenotic orifice of the valve and then expanded to a diameter greater than the valve annulus. On inflation of the balloon, valve dilation occurs in static position, and the radial transmission of stress allows not only for splitting of fused or incomplete leaflet commissures but also, perhaps of more importance, dilation and stretching of the annulus. If the diameter of the balloon is sufficiently large ( $\sim 120 \%-140 \%$ of the measured annulus diameter), the commissural tear(s) will often extend into the annulus itself, both enlarging it acutely and potentially allowing for remodeling and improved growth. ${ }^{8,9}$ Prior experience with palliative transcatheter valvuloplasty in patients with unrepaired TOF suggests that this technique may produce an increase in PV annular size beyond that expected with growth alone. ${ }^{10}$

The present study has 2 goals. The first is to observe and describe our institutional application of valve-sparing repair over time, the different modes by which it is achieved, and the predisposing anatomic and technical factors that may influence mode of repair. The second is to test the hypotheses 


$$
\begin{aligned}
& \text { Abbreviations and Acronyms } \\
& \begin{aligned}
\text { ANOVA }=\text { analysis of variance } \\
\text { CI } \quad=\text { confidence interval } \\
\text { IBPV }=\text { intraoperative balloon pulmonary } \\
\\
\text { valvuloplasty } \\
\text { OR }=\text { odds ratio } \\
\text { PR }=\text { pulmonary regurgitation } \\
\text { PV }=\text { pulmonary valve } \\
\text { RVOT }=\text { right ventricular outflow tract } \\
\text { TAP }=\text { transannular patch } \\
\text { TOF }=\text { tetralogy of Fallot }
\end{aligned}
\end{aligned}
$$

that TOF repair with IBPV promotes greater growth of the hypoplastic PV annulus than standard rigid dilation, with less resultant PR, and provides relief of RVOT obstruction comparable to standard rigid dilation or TAP.

\section{MATERIALS AND METHODS Inclusion Criteria}

In accordance with an accepted protocol from the Children's Hospital Boston Committee on Clinical Investigation, we performed a singlecenter, retrospective chart review of all patients with TOF and pulmonary stenosis who underwent complete primary repair at less than 180 days of age between January 1997 and April 2008. Individual patient consent was waived because of the retrospective nature of the study. Infants who underwent repair with placement of a right ventricular to pulmonary artery conduit or who had a history of catheter-based or surgical intervention or other complex coexisting cardiac disease (eg, complete atrioventricular canal) were excluded. Patients were divided into groups on the basis of the operative report description of surgical technique for relief of PV obstruction. We recognized 4 modes of repair: (1) TAP, (2) commissurotomy or standard rigid dilation (Hegar), (3) IBPV, and (4) no PV intervention (none). Patients were included in the group corresponding to the final mode of PV intervention (ie, patients who underwent initial rigid dilation, commissurotomy, or IBPV with subsequent intraoperative conversion to TAP were included in the TAP group). To gain insight into management of patients with mild to moderate PV hypoplasia, only patients with PV $z$ scores between -2 and -4 were included in the analysis.

\section{Baseline and Descriptive Data}

Demographic and surgical data included age and weight at repair, date of repair, surgeon, and categorization of repair technique at each level of the RVOT (subvalvar, valvar, and supravalvar). Preoperative echocardiographic data included diameters and $z$ scores of the PV and main and proximal branch pulmonary arteries. Immediate postoperative and most recent echocardiographic data included degree of PR and continuous-wave Doppler estimation of residual RVOT obstruction and right ventricular pressure by tricuspid regurgitation jet velocity. The timing of and indications for any reinterventions were recorded, as were any surgical or postoperative deaths.

\section{Comparison of Annular Growth, Valve Competence, and Residual Right Ventricular Outflow Tract \\ Obstruction}

For patients with significant PV hypoplasia ( $z$ score, -2 to -4 ) who underwent valve-sparing surgery (IBPV and Hegar groups), the most recent echocardiogram was reviewed from each of the following postoperative periods: immediate (<10 days), short-term (1-6 months), intermediate (6 months to 2 years), and long-term ( $>2$ years). For each available study, an independent observer (DWB or RR) who was blinded to the surgical technique reported the PV annulus diameter and $z$ score, continuouswave Doppler estimation of RVOT gradient and right ventricular pressure by tricuspid regurgitation jet velocity, and degree of PR $(1=$ trace, $2=$ mild, $3=$ moderate, or $4=$ severe). Grading of PR severity was based on synthesis of color Doppler jet width and flow reversal findings following previously published criteria. ${ }^{11,12}$

\section{Statistical Analysis}

Baseline differences in age and continuous echocardiographic variables between groups were tested using 1-way analysis of variance (ANOVA) with Bonferroni post hoc testing. Changes in $\mathrm{PV} z$ scores over time were assessed using repeated-measures ANOVA, also with application of the Bonferroni method of multiple comparisons. Differences in PV annular growth between groups were assessed by 2-way repeated-measures ANOVA. A linear mixed-effects model of PV annular growth, which would account for correlation among repeated measurements on the same subject, was also constructed. Comparisons of ordinal echocardiographic measures were performed using Friedman's test for multiple measurements in the 2 valve-sparing groups and the Kruskal-Wallis test for differences across all 3 groups. Interobserver variability for echocardiographic measurements was determined by the mean difference and distribution of differences between paired measurements for continuous variables, and weighted kappa using linear weights was calculated to assess agreement for ordinal data. Although a low event rate was anticipated, the times to any RVOT reintervention and to reoperation were estimated according to the method of Kaplan and Meier ${ }^{13}$ and by log-rank testing. Interventions directed at any level of the RVOT were counted, but cases of isolated branch pulmonary artery stenosis were not included. Given the low event rate and causes unrelated to the RVOT, surgical and postoperative mortality was characterized but not included in the Kaplan-Meier analysis. Unless noted otherwise, numbers in parentheses after mean and median values represent standard deviation and range, respectively.

The authors had full access to and take full responsibility for the integrity of the data. All authors have read and agree to the article as written.

\section{RESULTS}

\section{Inception Cohort}

A query of the surgical database identified 238 patients who met inclusion criteria for the descriptive portion of the study. Baseline age and weight at repair significantly differed among the 4 procedural groups, with patients having TAP undergoing repair at a younger age and smaller size (Table 1). Overall, 127 patients (53\%) had valve-sparing repair. PV and main pulmonary artery $z$ scores were smaller for the TAP and IBPV groups than for the other 2 valvesparing groups (Hegar and none). Patients in the IBPV group were more likely to undergo supravalvar patch augmentation than patients in the Hegar group (odds ratio [OR], 2.3; confidence interval [CI], 1.4-3.9; $P=.001)$.

\section{Study Cohort}

Of the 238 patients, $142(60 \%)$ had significant PV hypoplasia $(z$ score, -2 to -4$)$ and were included in the experimental analysis (Figure 1). Despite this attempt to create a more homogenous population, age, weight, and PV and main pulmonary artery diameter $z$ scores again differed significantly between groups, with a pattern similar to the larger initial cohort. 
TABLE 1. Baseline and procedural characteristics

\begin{tabular}{|c|c|c|c|c|c|}
\hline & $\begin{array}{c}\text { TAP } \\
\mathbf{n}=\mathbf{1 1 1}\end{array}$ & $\begin{array}{c}\text { IBPV } \\
\mathbf{n}=\mathbf{3 2}\end{array}$ & $\begin{array}{l}\text { Hegar } \\
\mathrm{n}=71\end{array}$ & $\begin{array}{c}\text { None } \\
\mathrm{n}=\mathbf{2 4}\end{array}$ & $P$ value \\
\hline Age at surgery (d) & $74 \pm 45^{*}, \dagger$ & $94 \pm 35$ & $93 \pm 41$ & $103 \pm 39$ & .001 \\
\hline Weight $(\mathrm{kg})$ & $4.56 \pm 1.46^{*}$ & $5.21 \pm 0.89$ & $5.04 \pm 1.35$ & $5.42 \pm 1.23$ & .005 \\
\hline PV $z$ score & $-2.79 \pm 0.95^{*}, \dagger$ & $-2.40 \pm 0.96^{*}, \dagger$ & $-1.43 \pm 1.09 *$ & $-0.77 \pm 1.20$ & $<.001$ \\
\hline Main pulmonary artery $z$ score & $-2.59 \pm 1.07 *, \dagger$ & $-2.39 \pm 1.61^{*}, \dagger$ & $-1.45 \pm 1.60^{*}$ & $0.05 \pm 1.92$ & $<.001$ \\
\hline \multicolumn{6}{|l|}{ Procedural characteristics } \\
\hline Muscle bundle resection & $108(97 \%)$ & $31(97 \%)$ & $69(97 \%)$ & $22(92 \%)$ & .56 \\
\hline RVOT patch & $108(97 \%)^{*}, \dagger$ & $29(91 \%)$ & $59(83 \%)$ & $15(63 \%)$ & $<.001$ \\
\hline Commissurotomy & $18(16 \%) \dagger, \ddagger$ & $27(84 \%)^{*}$ & $41(58 \%)^{*}$ & $0(0 \%)$ & $<.001$ \\
\hline Supravalvar patch & $108(97 \%)^{*}, \dagger, \ddagger$ & $18(56 \%)^{*}, \dagger$ & $17(24 \%)$ & $2(8 \%)$ & $<.001$ \\
\hline
\end{tabular}

*Significantly different from none. †ंSignificantly different from Hegar. Ł̦Significantly different from IBPV.

\section{Interobserver Reliability}

For the study portion, $36 \%$ of available studies were read by both blinded observers. There was strong interobserver agreement between paired measurements for all continuous variables (mean difference for PV diameter, $0.01 \mathrm{~cm} \mathrm{[95 \%}$ CI, -0.03 to 0.06], right ventricular pressure, $-0.18 \mathrm{~mm} \mathrm{Hg}$ [ $95 \% \mathrm{CI},-0.69$ to 0.32 ], and RVOT gradient, $1.31 \mathrm{~mm} \mathrm{Hg}$ [95\% CI, 0.26-2.35]), and good agreement for grading of PR (weighted kappa, 0.72).

\section{Intraoperative Balloon Pulmonary Valvuloplasty Technique}

While patients were on cardiopulmonary bypass and after sharp commissurotomy, a balloon was passed across the PV and inflated in a static position. The balloon was positioned

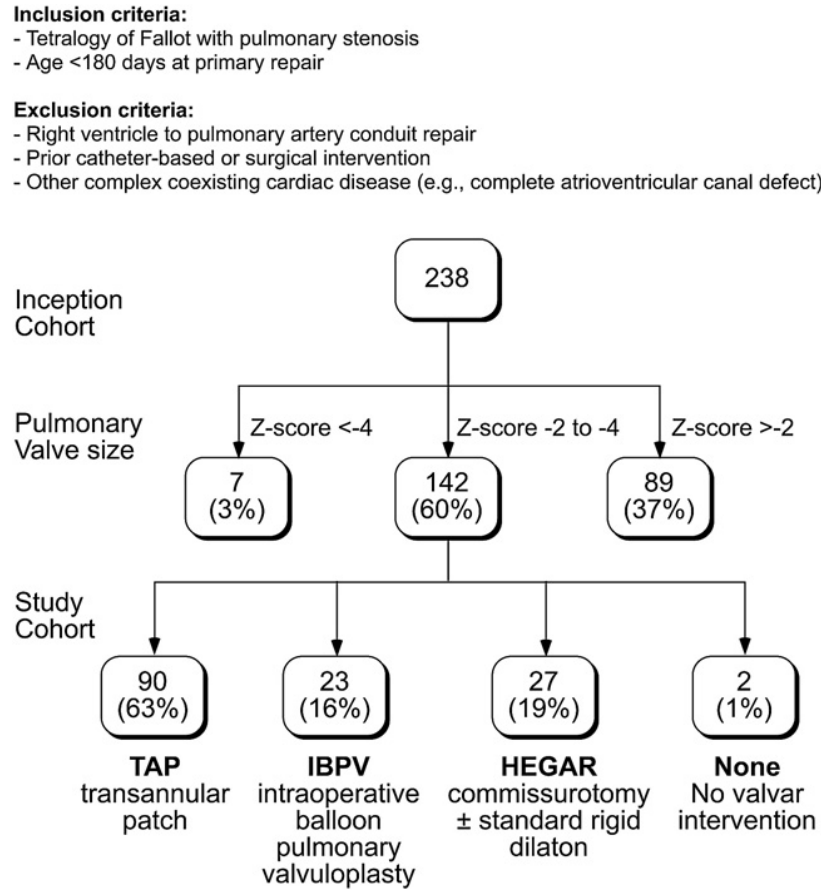

FIGURE 1. Identification of study groups. TAP, Transannular patch; $I B P V$, intraoperative balloon pulmonary valvuloplasty. antegrade across the RVOT, except in patients who did not undergo infundibulotomy and therefore had retrograde dilation $(2 / 32$ patients, $6 \%$ ). The size of the initial dilating balloon was determined by incorporation of the preoperative echocardiographic PV diameter measurement with intraoperative sizing using the largest, easily passable rigid dilator. In the 23 patients with significant PV hypoplasia who underwent IBPV, the initial median nominal balloon size to annulus ratio was $1.33(0.98-1.67)$. A median of 2 (1-3) different balloon sizes were used with a final nominal balloon size to annulus ratio of 1.47 (1.07-1.67). In 7 of 23 patients $(30 \%)$, the final balloon size was further modulated by inflation at high pressure ( $>8 \mathrm{~atm})$. Partial avulsion or tear of a single valve leaflet required pericardial patch valvuloplasty without TAP in 2 patients. Ineffective relief of PV stenosis $(n=1)$ and annular rupture $(n=2)$ required intraoperative conversion to TAP repair in 3 patients. As mentioned above, patients were included in the group corresponding to the final mode of PV intervention; thus, the latter 3 patients were included in the TAP experimental group, as were the 28 patients (28/111, or $25 \%$ of TAP group) who underwent rigid dilation or commissurotomy before intraoperative conversion to TAP.

\section{Annular Growth}

Median PV diameter and $z$ score were increased postoperatively and at all subsequent time points in both PV-sparing groups $(P<.001)$, although $\mathrm{PV} z$ scores were significantly lower in the IBPV group than in the Hegar group at all time points $(P=.005)$. At the most recent available assessment of PV size, both groups had normalization ( $z$ score, $>-2$ ) of median PV annulus size (Table 2). Figure 2 illustrates a linear mixed-effects model of annular growth during the first 3 postoperative years, with $\mathrm{PV} z$ score increasing 0.67 per year in the IBPV group $(P<.001)$ and 1.00 per year in the Hegar group $(P<.001)$. On average, both groups experienced significant $\mathrm{PV}$ growth over time, irrespective of preoperative PV size, but $z$ score was 0.58 lower for the IBPV group $(P=.001)$. The general patterns of change in $z$ score over time were not different between 
TABLE 2. Immediate postoperative and follow-up results for patients with significant preoperative PV hypoplasia $(z$ score, -2 to -4$)$

\begin{tabular}{|c|c|c|c|c|}
\hline & $\begin{array}{c}\text { TAP } \\
\mathbf{n}=\mathbf{9 0}\end{array}$ & $\begin{array}{l}\text { IBPV } \\
\mathrm{n}=\mathbf{2 3}\end{array}$ & $\begin{array}{l}\text { Hegar } \\
\mathbf{n}=\mathbf{2 7}\end{array}$ & $P$ value \\
\hline \multicolumn{5}{|l|}{ Postoperative } \\
\hline PV $z$ score & $\mathrm{n} / \mathrm{a}$ & $-2.14 \pm 0.66$ & $-1.34 \pm 1.28$ & .02 \\
\hline Change in PV $z$ score & $\mathrm{n} / \mathrm{a}$ & $0.77 \pm 0.73$ & $1.09 \pm 1.21$ & .33 \\
\hline RVOT gradient $(\mathrm{mm} \mathrm{Hg})$ & $20 \pm 13 \dagger$ & $34 \pm 16$ & $26 \pm 13$ & .003 \\
\hline More than mild PR & $97 \%(60 / 62)^{*}, \dagger$ & $32 \%(7 / 22)$ & $52 \%(11 / 21)$ & $<.001$ \\
\hline Severe PR & $79 \%(49 / 62)^{*}, \dagger$ & $5 \%(1 / 22)$ & $14 \%(3 / 21)$ & $<.001$ \\
\hline \multicolumn{5}{|l|}{ Follow-up } \\
\hline Median follow-up duration (y) & $5.1(0-11.6) \dagger$ & $1.5(0.4-3.5)$ & $5.8(0-11.9) \dagger$ & $<.001$ \\
\hline PV $z$ score & $\mathrm{n} / \mathrm{a}$ & $-1.44 \pm 1.08$ & $-1.07 \pm 1.39$ & .32 \\
\hline RVOT gradient $(\mathrm{mm} \mathrm{Hg})$ & $21 \pm 12$ & $29 \pm 13$ & $24 \pm 14$ & .06 \\
\hline More than mild PR & $93 \%(80 / 86)^{*}, \dagger$ & $50 \%(10 / 20)$ & $58 \%(15 / 26)$ & $<.001$ \\
\hline Severe PR & $85 \%(73 / 86)^{*}, \dagger$ & $15 \%(3 / 20)$ & $19 \%(5 / 26)$ & $<.001$ \\
\hline
\end{tabular}

*Significantly different from Hegar. $\dagger$ Significantly different from IBPV.

the 2 groups, and the interaction term was not statistically significant, suggesting that the rates of PV growth were not different between groups over this time period.

There were insufficient late data to adequately compare the groups beyond 3 years. Nonlinear models using the square root and natural log of time, which would assume more significant early growth, did not provide better fit than the simple linear model.

\section{Resultant Pulmonary Regurgitation and Reintervention}

Postoperatively, $97 \%$ of the TAP group had significant PR, and $32 \%$ of the TAP group had IBPV $(P<.001$, Table 2). This difference remained significant across all time points, although at the most recent follow-up, the incidence of significant PR had increased to $50 \%$ in the IBPV group. There were no significant differences in the degree of

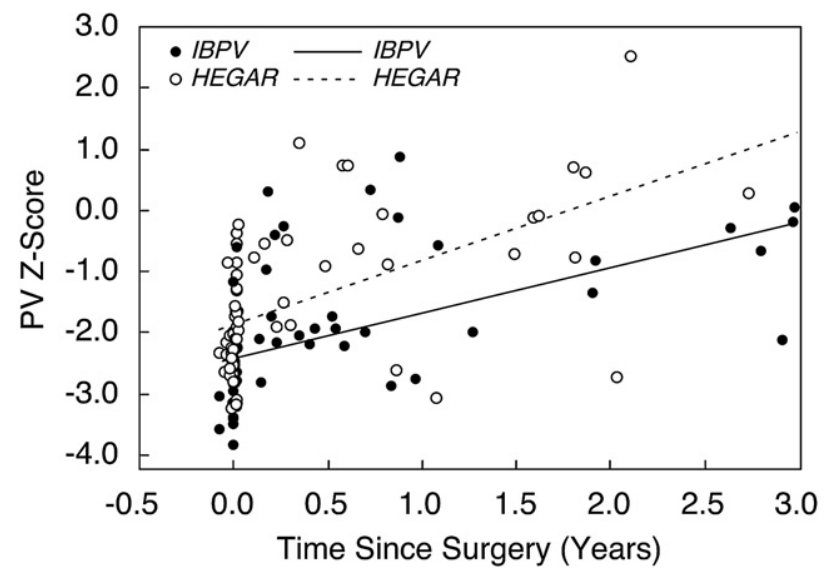

FIGURE 2. Linear mixed effects model of PV annular growth over time shows significant longitudinal growth in both valve-sparing groups $(P<.001$ for both Hegar and IBPV), but no significant difference in the rate or pattern of growth across groups. IBPV, Intraoperative balloon pulmonary valvuloplasty; $P V$, pulmonary valve.
PR between the IBPV and Hegar groups across all time points. One patient who had TAP repair underwent early PV replacement for PR at 8 years of age.

\section{Residual Right Ventricular Outflow Obstruction, Reintervention, and Survival}

The RVOT gradient was less in the TAP group than in the IBPV group postoperatively and approached statistical significance $(P=.06)$ at the most recent follow-up (Table 2). In all study patients, as well as the experimental population with significant PV hypoplasia, freedom from RVOT reintervention and surgery was significantly shorter for the IBPV group than the other groups by Kaplan-Meier analysis and log-rank testing $(P<.001$, Figure 3$)$. PV diameter and $\mathrm{PV} z$ score were not associated with reintervention on univariate analysis.

Overall, 10 of 142 study patients (7\%) underwent reintervention for residual RVOT obstruction. Six patients $(26 \%)$ underwent reintervention after IBPV; 2 were successfully treated with transcatheter balloon valvuloplasty alone, and the remaining 4 had surgical treatment for isolated valvar obstruction after unsuccessful catheter-based therapy $(\mathrm{n}=1)$, subvalvar muscular obstruction $(\mathrm{n}=2)$, and emergency repair of pulmonary artery laceration sustained during balloon dilation of combined valvar and supravalvar pulmonary stenosis $(\mathrm{n}=1)$. Two patients $(7 \%)$ in the Hegar group underwent reintervention for RVOT obstruction; 1 had successful transcatheter therapy and 1 underwent further muscle bundle resection after catheterization. Two patients $(2 \%)$ in the TAP group had residual RVOT obstruction at the level of the main and branch pulmonary arteries, which was successfully treated in the catheterization laboratory.

In the TAP group, there was 1 operative death due to disseminated pulmonary and coronary artery thromboses. There were 3 late deaths, 1 in the Hegar group and 2 in the TAP group. The patient in the Hegar group and 1 of 

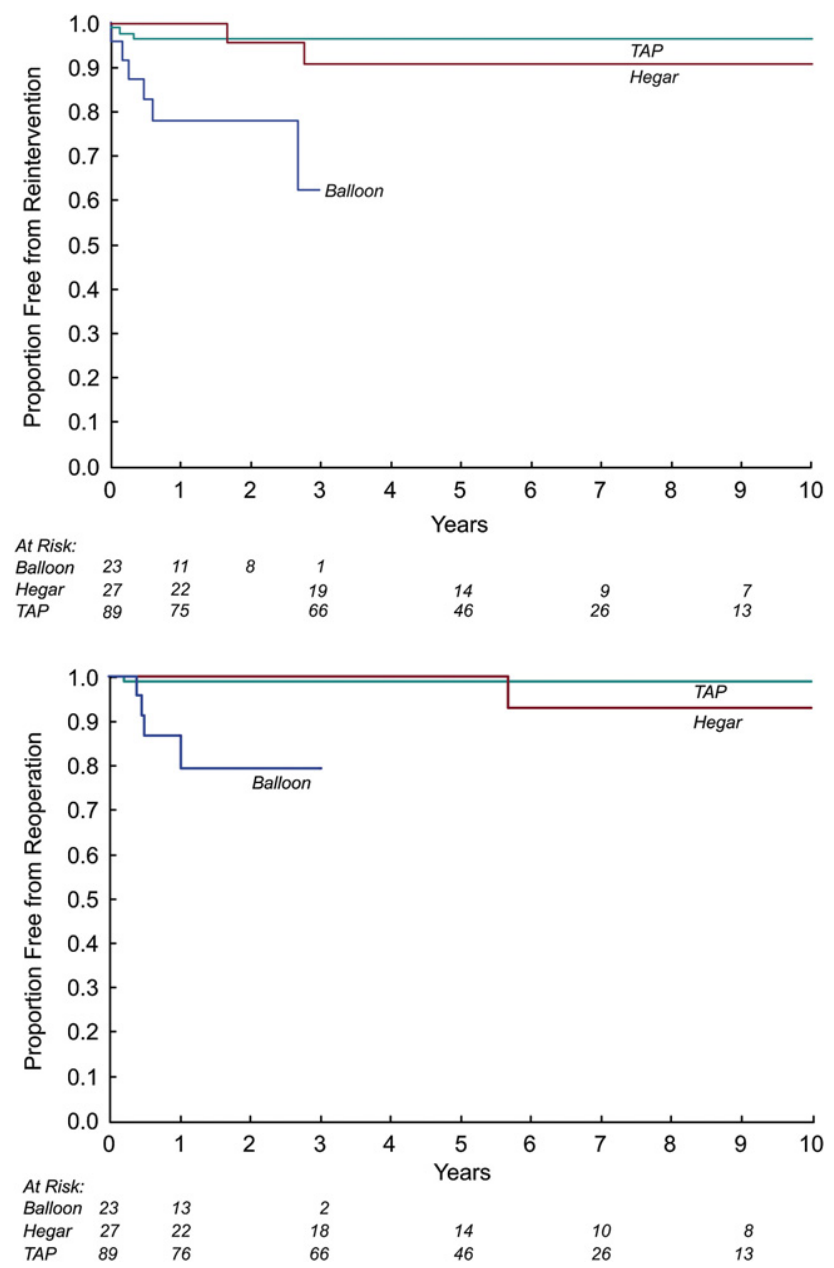

FIGURE 3. Freedom from reintervention and reoperation functions by PV intervention type for patients with significant PV hypoplasia. Kaplan-Meier curves are pictured for the study group only, but were similar for the entire inception cohort. One intraoperative death in the TAP group is not included in the analysis but is described in the text. TAP, Transannular patch.

the patients in the TAP group both had chromosomal abnormalities, multiple congenital anomalies, and airway compromise resulting in respiratory failure. The other death in the TAP group occurred in a patient with diminutive pulmonary arteries who had a complicated postoperative course significant for failure to separate from bypass, extracorporeal membrane oxygenation, multiple catheterizations for bilateral pulmonary artery stenosis, delayed chest closure, capillary leak syndrome, and recurrent sepsis. These cases were not included in the RVOT reintervention analysis.

\section{DISCUSSION}

The important long-term consequences of PR have reframed the question of what constitutes acceptable or manageable residual RVOT obstruction. Several techniques are used to relieve RVOT obstruction in patients undergoing

TOF repair, each with different implications for the degree of residual obstruction and for PV competence. Given these clinical concerns and the real and theoretic advantages of IBPV, we have applied this innovative procedure to a heterogeneous group of patients during the past 4 years. Retrospectively, we compared IBPV with more traditional surgical methods and analyzed short-term outcomes to learn more about potential application to the subset of patients likely to benefit most from this technique. This study represents our initial experience with the balloon pulmonary valvotomy technique as a valve-sparing approach to tetralogy repair in infants.

Descriptive characterization of baseline anatomy and mode of repair confirmed broad historical variation in surgical decision-making. Among surgeons who performed at least 10 repairs before the introduction of IBPV (5 surgeons, 166 procedures), the percentage of cases in which a TAP repair was performed ranged from $31 \%$ to $80 \%$ among surgeons. There was substantial overlap among all procedural groups. However, the frequency of valvesparing surgery increased over time and must at least in part reflect growing surgeon preference for PV preservation. In fact, 2 of the 7 surgeons accounted for the majority of total valve-sparing procedures ( $16 / 23$ patients, or $70 \%$ of the IBPV group; $19 / 27$ patients, or $70 \%$ of the Hegar group) but only $38 \%$ of all repairs. Furthermore, the more contemporary patients with IBPV were anatomically similar to patients with TAP, with significantly more RVOT hypoplasia than those who underwent traditional rigid dilation or commissurotomy. This is reflected in the lower preoperative PV $z$ score in the IBPV group compared with the Hegar group. It is not surprising that the IBPV and TAP groups were also more likely to have concomitant supravalvar intervention. This suggests that for valve-sparing TOF surgery to gain more acceptance among surgeons, precise morphologic criteria should be identified that can guide surgical therapy.

The prenatal and preoperative quantitative anatomy of unrepaired TOF has been well defined and is widely variable across each level of the RVOT and between individuals. ${ }^{14-16}$ Although several groups have demonstrated PV growth after palliative balloon valvuloplasty for unrepaired TOF, ${ }^{10,17,18}$ little is currently known about annular growth after complete PV-sparing repair. Surgical reports focused on valve-sparing strategies have reported generally good outcomes, ${ }^{19-22}$ but longitudinal assessment of PV size is limited and described in mildly hypoplastic cohorts. $^{20,22}$ In our study, all patients who underwent PVsparing surgery had significant longitudinal annular growth, with eventual normalization of PV annular diameter over time, and a lower incidence of significant PR than in TAP repair. Counter to our study hypothesis, the IBPV group did not experience significantly greater annular growth or have significantly less postoperative PR than patients who had commissurotomy or rigid dilation. However, IBPV 
was used in patients with significantly greater PV hypoplasia across all time points.

Despite substantial PV annular growth and normalization of PV hypoplasia, IBPV was associated with higher shortterm reintervention rates compared with TAP, suggesting that annular dimension is not the sole determinant of successful valve-sparing repair. Although reintervention after IBPV was predominantly for residual RVOT obstruction, only 3 of 6 patients $(50 \%)$ required reintervention for isolated valvar obstruction. Two of these patients had catheter-based therapy alone, whereas the single patient who had surgical reintervention had a dysplasticappearing valve with only mild PV annular hypoplasia ( $z$ score, -2.63$)$ at the time of reoperation. This is consistent with prior observation that valve morphology may be an important determinant of PV-sparing repair. ${ }^{19}$ Moreover, the other $50 \%$ of patients requiring reintervention had subval$\operatorname{var}(\mathrm{n}=2)$ and combined valvar and supravalvar obstruction $(\mathrm{n}=1)$. Finally, PV diameter and PV $z$ score were not associated with reintervention.

These findings are further evidence that treatment of annular hypoplasia is only one of several important factors in achieving successful PV-sparing repair and have already prompted considerable changes in surgical technique as the IBPV procedure has evolved. Inadequate commissurotomy, under-aggressive balloon dilation, incomplete muscle bundle resection, and, in particular, failure to patch the supravalvar area have all been raised as potential contributors to higher short-term reintervention rates. We have subsequently modified the supravalvar incision, extending it in a T-shape into the commissures of the PV and extending the infundibular patch into the commissures. Further evaluation of these more recent modifications is required to determine their efficacy in preventing reintervention for residual or recurrent outflow obstruction.

Although TAP was associated with the lowest reintervention rate, these patients had a greater degree of PR. The higher degree of residual RVOT obstruction associated with IBPV is concerning; however, the long-term effects of moderate RV pressure overload in repaired TOF remain less certain ${ }^{22}$ than those associated with severe $\mathrm{PR}^{5-7}$ and deserve ongoing follow-up. In addition, the proportion of patients with residual RVOT obstruction who were successfully treated by catheter-based therapy alone $33 \%$ of all patients requiring intervention after IBPV, $66 \%$ of patients with isolated valvar obstruction) may be a compelling argument for further refinement.

Given the desire to preserve valve competence, the significant PV growth with normalization of hypoplasia after IBPV, and the relative success of catheter-based therapy, this technique may have an evolving role as an additional tool to achieve valve-sparing repair in selected patients, particularly those with a PV $z$ score between -2.5 and -3.5 and who might have received a TAP previously.

\section{CONCLUSIONS}

Patients with TOF and significant PV hypoplasia who have valve-sparing repair with IBPV, rigid dilation, or commissurotomy have significant longitudinal PV growth, with normalization of annular size over time. IBPV resulted in similar PV growth and postoperative PR as traditional methods, despite being used in a more hypoplastic patient cohort. In this initial series that included our learning curve, IBPV was associated with higher degrees of residual RVOT obstruction, and consequently higher rates of reintervention, than TAP repair or traditional valve-sparing techniques, but it is an evolving technique that merits further refinement and study.

The authors thank Kimberlee Gauvreau for invaluable assistance with statistical analysis and Emily Harris for assistance with the preparation of Figures 1 to 3 .

\section{References}

1. Sung SC, Kim S, Woo JS, Lee YS. Pulmonic valve annular enlargement with valve repair in tetralogy of Fallot. Ann Thorac Surg. 2003;75:303-5.

2. Anagnostopoulos P, Azakie A, Natarajan S, Alphonso N, Brook MM, Karl TR. Pulmonary valve cusp augmentation with autologous pericardium may improve early outcome for tetralogy of Fallot. J Thorac Cardiovasc Surg. 2007;133: 640-7.

3. Bacha EA, Marshall AC, McElhinney DB, del Nido PJ. Expanding the hybrid concept in congenital heart surgery. Semin Thorac Cardiovasc Surg. 2007; 146-50.

4. Bigras JL, Boutin C, McCrindle BW, Rebeyka IM. Short-term effect of monocuspid valves on pulmonary insufficiency and clinical outcome after surgical repair of tetralogy of Fallot. J Thorac Cardiovasc Surg. 1996;112:33-7.

5. Helbing WA, Niezen RA, Le Cessie S, van der Geest RJ, Ottenkamp J, de Roos A. Right ventricular diastolic function in children with pulmonary regurgitation after repair of tetralogy of Fallot: volumetric evaluation by magnetic resonance velocity mapping. J Am Coll Cardiol. 1996;28:1827-35.

6. Gatzoulis MA, Balaji S, Webber SA, Siu SC, Hokanson JS, Poile C, et al. Risk factors for arrhythmia and sudden cardiac death late after repair of tetralogy of Fallot: a multicentre study. Lancet. 2000;356:975-81.

7. Geva T, Sandweiss BM, Gauvreau K, Lock JE, Powell AJ. Factors associated with impaired clinical status in long-term survivors of tetralogy of Fallot repair evaluated by magnetic resonance imaging. J Am Coll Cardiol. 2004;43: 1068-74.

8. Radtke W, Keane JF, Fellows KE, Lang P, Lock JE. Percutaneous balloon valvotomy of congenital pulmonary stenosis using oversized balloons. J Am Coll Cardiol. 1986;8:909-15

9. Ring JC, Kulik TJ, Burke BA, Lock JE. Morphologic changes induced by dilation of the pulmonary valve anulus with overlarge balloons in normal newborn lambs. Am J Cardiol. 1985;55:210-4.

10. Sluysmans T, Neven B, Rubay J, Lintermans J, Ovaert C, Mucumbitsi J, et al. Early balloon dilatation of the pulmonary valve in infants with tetralogy of Fallot. Risks and benefits. Circulation. 1995;91:1506-11.

11. Goldberg SJ, Allen HD. Quantitative assessment by Doppler echocardiography of pulmonary or aortic regurgitation. Am J Cardiol. 1985;56:131-5.

12. Frigiola A, Redington AN, Cullen S, Vogel M. Pulmonary regurgitation is an important determinant of right ventricular contractile dysfunction in patients with surgically repaired tetralogy of Fallot. Circulation. 2004;110(11 Suppl. 1): II153-7.

13. Kaplan EL, Meier P. Nonparametric estimation from incomplete observations. $J$ Am Stat Assoc. 1958;53:457-81.

14. Lev M, Rimoldi JA, Rowlatt UF. The quantitative anatomy of cyanotic tetralogy of Fallot. Circulation. 1964;30:531-8.

15. Shimazaki Y, Blackstone EH, Kirklin JW, Jonas RA, Mandell V, Colvin EV. The dimensions of the right ventricular outflow tract and pulmonary arteries in tetralogy of Fallot and pulmonary stenosis. J Thorac Cardiovasc Surg. 1992;103: 692-705. 
16. Hirji A, Bernasconi A, McCrindle BW, Dunn E, Gurofsky R, Manlhiot C, et al. Outcomes of prenatally diagnosed tetralogy of Fallot: implications for valvesparing repair versus transannular patch. Can J Cardiol. 2010;26:e1-6.

17. Sreeram N, Saleem M, Jackson M, Peart I, McKay R, Arnold R, et al. Results of balloon pulmonary valvuloplasty as a palliative procedure in tetralogy of Fallot. $J$ Am Coll Cardiol. 1991;18:159-65.

18. Matsuoka S, Ushiroguchi Y, Kubo M, Tatara K, Kitagawa T, Katoh I, et al. Balloon pulmonary valvuloplasty for infants with severe tetralogy of Fallot. Jpn Heart J. 1993;34:643-51.

19. Stewart RD, Backer CL, Young L, Mavroudis C. Tetralogy of Fallot: results of a pulmonary valve-sparing strategy. Ann Thorac Surg. 2005;80:1431-9.
20. Parry AJ, McElhinney DB, Kung GC, Reddy VM, Brook MM, Hanley FL. Elective primary repair of acyanotic tetralogy of Fallot in early infancy: overall outcome and impact on the pulmonary valve. J Am Coll Cardiol. 2000;36: 2279-83.

21. Voges I, Fischer G, Scheewe J, Schumacher M, Babu-Narayan SV, Jung O, et al. Restrictive enlargement of the pulmonary annulus at surgical repair of tetralogy of Fallot: 10-year experience with a uniform surgical strategy. Eur J Cardiothorac Surg. 2008;34:1041-5.

22. Boni L, Garcia E, Galletti L, Perez A, Herrera D, Ramos V, et al. Current strategies in tetralogy of Fallot repair: pulmonary valve sparing and evolution of right ventricle/left ventricle pressures ratio. Eur J Cardiothorac Surg. 2009;35:885-90. 